\title{
Discussion and Consideration on Urban Standardization Strategic Planning

\author{
Linfeng $\mathrm{Wu}$
}

China National Institute of Standardization, Beijing, 100191

\begin{abstract}
In the face of the new situation that our country's economy has been to high-quality development stage put forward by the 19th National Congress of the Communist Party of China, the Standardized strategic planning of provinces and cities developed in China was briefly introduced and analyzed, the paper, taking Zhangjiakou as an example, briefly analyzes the principles of the city needing to be considered to develop high quality standardization strategic planning, combing with the advanced experience and practices of standardization strategic planning of provinces and cities, and the paper simple discusses the problems of technology consulting and their own research carried on during the development process of urban standardization strategic planning.
\end{abstract}

Keywords: High quality development; urban standardization planning; principle; technical consulting.

\section{关于城市标准化战略规划的探讨与思考}

\author{
吴林峰 \\ 中国标准化研究院，北京，100191
}

摘 要: 面对十九大提出的我国经济已向高质量发展阶段转变的新形势, 对我国各省市制定的 标准化战略规划进行了梳理和简要分析, 结合并借鉴各省市标准化战略规划中的先进经验和 做法, 以张家口市为例, 简要分析了制定高质量的城市标准化战略规划需要考虑的原则, 并 对城市标准化战略规划制定过程中涉及的技术咨询与自身研究的问题进行了简单探讨。

关键词: 高质量发展; 城市标准化规划; 原则; 技术咨询

\section{1. 前言}

中国特色社会主义已经进入新时代, 党的十九大指出当前我国经济已由高速增长阶段转向高 质量发展阶段, 正处在转变发展方式、优化经济结构、转换增长动力的攻关期。通过高质量 发展可有效优化经济结构, 从而构建现代化经济体系。早在2014年, 习近平总书记就提出 “标 准决定质量, 有什么样的标准就有什么样的质量, 只有高标准才有高质量。”因此通过标准提 升、标准化规划引领发展, 是保障产品和服务质量, 促进供给侧结构性改革的重要方向。此 外, 推动产业转型升级, 就是要提高供给侧质量, 是推动现代化经济体系建设的重要内容。

【1】国家的高质量发展、转型升级离不开城市产业发展和提升, 当前我国各大省市（区）纷 纷制定了促进地区产业高质量发展的标准化战略规划, 同时, 很多政府机构为了保障战略规 划制定的科学性和高质量进行了大量的技术咨询, 然而城市如何制定高质量的标准化规划, 怎样提升和改进城市标准化规划的针对性和实用性是一个值得探讨的问题。

\section{2. 城市标准化规划}

标准是通过标准化活动, 按照规定的程序经协商一致制定, 为各种活动或其结果提供规则、 指南或特性, 供共同使用和重复使用的文件。【2】标准化学科与管理学的关系在于: 标准化 学科在理论上是研究对行为的引导和控制, 与管理学密切相关。【3】而城市标准化规划正是 利用了标准的规范性、引导性、可共同使用这三个属性, 为统筹城市发展而对城市布局和各 项建设的综合部署, 它结合城市产业发展, 以标准化为工具手段, 一般从城市规划、市政工 程、建筑工程、基础设施建设、使用、维护等方面, 围绕提升城乡建设与管理进行的设计, 
是一定时期内城市发展的蓝图, 也是城市管理的重要组成部分。它有助于解决城市发展中遇 到的现实以及潜在问题, 是促进城市产业结构调整、发展方式转变、转型升级的重要手段。

\section{3. 我国城市标准化规划现状}

国外对标准化战略规划的研究已经有很长的历史, 欧美等发达国家很多都制定了国家标准化 战略【4】, 并进行不断更新和完善。国外标准化战略规划的制定在保障其国家产品和服务质 量、加强内部管理、促进国际合作等方面发挥了重要作用。2016年，习近平总书记在致第39 届 ISO 大会的贺信中明确指出: 中国将积极实施标准化战略。国内大量城市以服务城市经济 社会发展为主线, 落实深化标准化工作改革要求, 着力推动实施标准化战略, 他们充分利用 标准化这个工具, 开展了大量标准化服务经济社会各领域应用与融合方面的深入研究和实践。 这对于保障产品和服务质量, 提升产业整体水平和竞争实力, 促进经济发展方式转变, 提高 发展质量等方面发挥了重要作用。

\section{1 相关规划情况}

地方标准化规划反映了地方政府在标准化与质量提升方面前期所做的工作部署与设计。截至 2017年12月底, 在不含香港、澳门和台湾地区的31个省、自治区、直辖市中, 已有 26 个已发 布地方标准化战略性文件、规划。表1列出了相关文件、规划的名称等信息。

\section{2 规划简要分析}

这些文件多以战略纲要、省市政府加强相关工作意见、发展规划、行动计划等形式出现, 对 各地标准化工作的总体要求、发展目标、主要任务、重点工作、配套措施等内容进行了规划 设计。这些规划相关的文件主要以 “政府推动、市场导向、企业主体、社会参与” 作为工作 的导向, 结合各省市产业特色和发展重点, 在标准化方面, 提出了健全标准体系、强化标准 实施应用、加强标准监督管理、营造社会共治氛围、加强国际标准化工作、夯实标准化工作 基础等工作重点, 各地区根据各地特点, 一般都是从农业农村、工业、服务业、社会管理及 公共服务、生态文明建设几个层面制定相应措施, 保证标准化规划的实施。标准化规划文件 的发布和实施, 为引领和推动地方产业结构的调整优化升级, 促进地方经济发展方式的转变, 提升区域核心竞争力，提升社会管理和公共服务水平等工作发挥了有力支撑作用。

\section{4. 规划制定的相关原则}

通过对国内各省市标准化规划的梳理和初步汇总分析, 发现各省市相关规划一般都是在落实 国家相关标准化战略、政策、方针要求基础上, 结合当地产业、经济特色和优势进行相应的 完善和细化, 各有特色, 各省市标准化规划中先进的理念、模式和方法对其他城市标准化规 划有一定参考借鉴价值。要提升城市标准化规划的质量, 需要遵循和考虑以下几项原则。笔 者以张家口市标准化规划的制定为例, 进行一下具体介绍和分析。

\section{1 整合原则}

\subsection{1 要与城市的经济技术发展水平相适应}

经过长期发展, 张家口市各产业正在不断发展, 标准体系也在不断完善, 质量水平也在稳步 提升。但是张家口市经济总量仍然偏小，战略性新兴产业尚未形成规模，标准对经济社会发 展的支撑力还没有充分发挥。因此张家口应该充分发挥自身优势, 寻找借鉴, 比如重点发展 的绿色能源、旅游、服务产业，可借鉴《安徽省标准化体系建设发展规划（2016-2020年）》 模式, 其在发展规划的第三部分 “重点领域” 中设置了 “服务业标准化重点” 专栏, 针对旅 
游、服务外包、交通运输标准化领域进行了有针对性的规划。具体的发展旅游方面标准化工 作可以参照各地区旅游标准化发展规划的相关设计方案。

表1 各省、自治区、直辖市标准化相关文件、规划一览表

\begin{tabular}{|c|c|c|c|}
\hline $\begin{array}{l}\text { 序 } \\
\text { 号 }\end{array}$ & 地区 & 标准化与质量提升相关规划 & 日期或文号 \\
\hline \multirow{3}{*}{1.} & \multirow{3}{*}{ 云南省 } & 云南省人民政府关于实施标准化发展战略的意见 & 云政发（2009）143号 \\
\hline & & 云南省人民政府办公厅关于加快推进标准化体系建设的实施意见 & $\begin{array}{c}\text { 云政办发〔2016〕149 } \\
\text { 号 }\end{array}$ \\
\hline & & 云南省开展基层政务公开标准化规范化试点工作方案 & 2017. 08.25 \\
\hline \multirow{3}{*}{2.} & \multirow{3}{*}{ 贵州省 } & 贵州《省人民政府关于加强标准化工作的若干意见》 & 2010.05 .04 \\
\hline & & 贵州省标准化体系建设发展规划 (2016-2020年) & 2016.12 .26 \\
\hline & & 贵州省开展基层政务公开标准化规范化试点实施方案 & 2017.08 .24 \\
\hline \multirow{2}{*}{3.} & \multirow[b]{2}{*}{ 北京市 } & 首都标准化战略纲要 & 2011.08 .01 \\
\hline & & 北京市人民政府关于进一步加强城市管理与服务标准化建设的意见 & 京政发[2015]41号 \\
\hline \multirow[b]{2}{*}{4.} & \multirow{2}{*}{ 四川省 } & 四川省标准化体系建设发展规划（2016-2020年） & 2016.12 .18 \\
\hline & & 四川省开展基层政务公开标准化规范化试点工作实施方案 & 2017.09 .06 \\
\hline 5. & 湖南省 & 湖南省标准化发展规划纲要 $(2010-2020$ 年) & 2010.01 .15 \\
\hline 6. & 吉林省 & 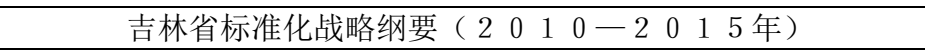 & 2010.07 .09 \\
\hline 7. & 陕西省 & 陕西省标准化发展战略纲要（2011－2020年） & 2012.10 .11 \\
\hline 8. & 甘肃省 & 甘肃省标准化发展战略纲要（2014一-2020年） & 2014.11 .15 \\
\hline 9. & 天津市 & 天津市实施标准化战略十三五规划 & 2015.12 .15 \\
\hline 10. & 江西省 & 江西省标准化体系建设发展规划（2016-2020年） & 2016.04 .29 \\
\hline 11. & 辽宁省 & 辽宁省标准化体系建设发展规划（2016一-2020年） & 2016.05 .08 \\
\hline 12. & 河北省 & 河北省标准化体系建设发展规划 (2016-2020年) & 2016.06 .14 \\
\hline 13. & 浙江省 & 浙江省 “标准化+” 行动计划 & 2016.07 .18 \\
\hline 14. & 安徽省 & 安徽省标准化体系建设发展规划（2016-2020年） & 2016.07 .26 \\
\hline 15. & 上海市 & 上海市标准化体系建设发展规划（2016-2020年） & 2016.08 .15 \\
\hline 16. & 内蒙古自治区 & 内蒙古自治区标准化体系建设发展规划（2016-2020年） & 2016.11 .14 \\
\hline 17. & 湖北省 & 湖北省标准化体系建设发展规划（2016-2020年） & 2016.11 .30 \\
\hline 18. & $\begin{array}{c}\text { 宁夏回族自治 } \\
\text { 区 }\end{array}$ & 宁夏回族自治区标准化体系建设发展规划 & 2017. 02.24 \\
\hline 19. & 山西省 & 全省推进标准化工作改革发展2017-2018年行动计划（山西省） & 2017.06 .26 \\
\hline 20. & 重庆市 & 重庆市人民政府关于实施标准战略切实加强标准化工作的意见 & 渝府发 (2006) 65号 \\
\hline 21. & 河南省 & 河南省人民政府关于实施标准化战略的意见 & 豫政〔2007)28号 \\
\hline 22. & 青海省 & $\begin{array}{c}\text { 青海省人民政府办公厅转发省质量技术监督局关于实施标准化战略 } \\
\text { 意见的通知 } \\
\end{array}$ & 青政办 〔2007〕95号 \\
\hline 23. & $\begin{array}{c}\text { 广西壮族自治 } \\
\text { 区 }\end{array}$ & 广西壮族自治区人民政府关于实施技术标准发展战略的意见 & 桂政发〔2008〕55号 \\
\hline 24. & 山东省 & 山东省人民政府关于实施标准化战略的意见 & 鲁政发（2009）84号 \\
\hline 25. & 海南省 & 海南省人民政府关于实施标准化战略的意见 & 琼府 (2011) 15号 \\
\hline 26. & $\begin{array}{l}\text { 新疆维吾尔自 } \\
\text { 治区 }\end{array}$ & 新疆维吾尔自治区标准化发展战略纲要（2011一2020年） & 新政发〔2013〕19号 \\
\hline
\end{tabular}

注：统计中不包含各省（市）“消费品标准升级和质量提升规划”。

另外，据不完全统计，有24个市制定并发布了标准化相关规划，统计情况如表2所示。

4. 1.2 要正确处理好局部建设和整体发展的辩证关系

城市标准化规划既要结合自身特点做好规划设计, 又要根据当前城市发展面临的各种形势, 充分反映各级要求的宏观规划设计。以张家口为例, 首先, 从京津冀协同发展、河北一翼两 个方面考虑，张家口市发展规划应该服务北京市以及河北省整体发展规划布局。如《京津冀 协同发展规划纲要》、《河北省标准化体系建设发展规划 (2016-2020年)》、《北京市人民政 府关于进一步加强城市管理与服务标准化建设的意见》（京政发 [2015]41号）等，其中后者 提出了要 “建立京津冀标准化工作定期沟通协调机制和强制性地方标准通报协商机制，加强 信息共享，定期交换地方标准文本”，因此张家口市标准化发展规划中应该有所体现和呼应。 
特别是要按照习总书记对冬奥会筹办的一些要求进行设计考虑, 并做好同北京冬奥会筹办总 体规划、北京市筹办规划的紧密对接。

表2 全国各市标准化相关规划一览表

\begin{tabular}{|c|c|c|c|}
\hline $\begin{array}{l}\text { 序 } \\
\text { 号 }\end{array}$ & 地区 & 标准化与质量提升相关规划 & 日期 \\
\hline 1. & 永州市 & 永州市标准化发展规划纲要 $(2010-2020$ 年) & 2010.08 .26 \\
\hline 2. & 深圳市 & 深圳市知识产权与标准化战略纲要（2011一2015年） & 2011.12 .23 \\
\hline 3. & $\begin{array}{l}\text { 北京市 } \\
\text { 昌平区 }\end{array}$ & $\begin{array}{c}\text { 北京市昌平区人民政府关于印发贯彻落实《首都标准化战略纲要》和《北京市 “十二 } \\
\text { 五” 时期标准化发展规划》实施意见的通知 }\end{array}$ & 2012. 08. 03 \\
\hline 4. & 广州市 & 广州市标准化战略实施纲要 (2013-2020年) & 2013.07 .25 \\
\hline 5. & 三亚市 & 三亚市标准化发展规划 & 2016.03 .21 \\
\hline 6. & 庆阳市 & 庆阳市《2016年标准化工作计划》 & 2016.03 .24 \\
\hline 7. & 潍坊市 & 潍坊市人民政府关于加快实施标准化战略的意见 & 2016.04 .25 \\
\hline 8. & 沈阳市 & 沈阳市标准化体系建设发展规划 (2016-2020年) & 2016.06 .14 \\
\hline 9. & 沧州市 & 沧州市标准化体系建设发展规划（2016一-2020年） & 2016. 11.09 \\
\hline 10. & 宿州市 & 宿州市标准化体系建设发展规划 (2016-2020年) & 2016.11 .18 \\
\hline 11. & $\begin{array}{l}\text { 石家庄 } \\
\text { 市 }\end{array}$ & 石家庄市标准化体系建设发展规划（2016-2020年） & 2016. 12.16 \\
\hline 12. & 杭州市 & 关于实施 “标准化+” 行动计划, 提升城市国际化水平的实施方案 & 2016.12 .23 \\
\hline 13. & 临汾市 & 临汾市标准化体系建设发展规划（2016-2020年） & 2016. 12.27 \\
\hline 14. & 宣城市 & 宣城市标准化体系建设发展规划（2016-2020年） & 2017.02 .15 \\
\hline 15. & 青岛市 & 青岛市“标准化+” 发展规划（2016一2020年） & 2017.02 .24 \\
\hline 16. & 大连市 & 大连市标准化体系建设发展规划（2016一-2020年） & 2017.03 .21 \\
\hline 17. & 蚌埠市 & 蚌埠市标准化体系建设发展规划 (2016-2020年) & 2017.04 .18 \\
\hline 18. & 银川市 & 银川市标准化体系建设发展规划（2016一-2020年） & 2017.05 .08 \\
\hline 19. & 日照市 & 日照市标准化 “十三五” 发展规划 & 2017.06 .24 \\
\hline 20. & 乐山市 & 乐山市标准化体系建设发展规划（2016一-2020 年） & 2017.08 .15 \\
\hline 21. & 中卫市 & 中卫市标准化体系建设发展规划（2016-2020年） & 2017.12 .05 \\
\hline
\end{tabular}

4.1.3 要正确处理好城市规划与远期发展的辩证关系

首先, 从规划的长远性、前瞻性角度考虑, 结合张家口市长远发展的目标来看, 可以参照发 达地区、省市，取得比较好的发展成效的规划来进行总体提升。如《深圳市人民政府打造深 圳标准构建质量发展新优势行动计划（2015-2020年）》提到一项措施 “发挥国家自主创新 示范区对标准创新的推动作用。将标准创新纳入国家自主创新示范区建设, 发挥综合创新生 态体系优势, 搭建国际化标准创新平台, 提升深圳标准创新能力。” 结合张家口市实际情况, 短期内还不能达到这种程度，不能完全照搬，但是可以充分利用靠近首都的优势等，利用建 设首都水源涵养功能区和生态环境支撑区、建设可再生能源示范区和河北一翼等重大历史机 遇, 先从创新能力培育, 吸引人才等方面进行提前规划布局。其次, 规划既要立足长远, 又 要妥善应对当前面临的机遇和挑战, 在针对需要解决的重大首要问题基础上进行拓展和不断 延伸。从当前紧急需求和形势发展的角度考虑, 张家口市发展规划还应紧紧抓住筹办冬奥会、 京津冀协同发展的大趋势、大机遇加快发展。

\section{2 经济原则}

\section{2.1 找准定位, 促进发展}

首先, 应该找准定位, 认识到自身发展受到种种因素限制, 前期多年的发展过程中还存在一 些困难, 因此发展规划在参照欠发达地区方面可以重点借鉴, 例如《甘肃省标准化发展战略 纲要（2014-2020年）》的主要任务（一）“重视标准化工作基础，增强我省标准化发展后 劲” 中使用的 “成果专利化、专利标准化、标准产业化” 原则, 提出要加强标准研制与技术 创新、产业发展的衔接配套，把标准列入省级科技计划项目立项评价指标等设计，这些规划 设计特别适用于标准化发展基础相对薄弱的地区利用标准来促进经济发展。此外，考虑到当 
前国家机构改革涉及到的地方政府部门机构改革的现实局面, 以及新标准化法刚开始实施等 新形势，这些在规划中都应该做到提前考虑。

\section{2.2 注重实施, 推动发展}

规划制定的目的是要通过实施来推进张家口市质量提升和经济发展, 因此规划的落实和实施 就特别重要, 因此在规划的制定过程中就好考虑推进实施。例如《广东省实施质量强省战略 2016-2017年行动计划》以及张家口市前期发布的《中共张家口市委张家口市人民政府关于实 施质量强市和标准化战略的意见》最后都针对每一项任务设置了牵头部门和责任单位, 切实 做到了责任落到部门负责, 有力保障了工作任务的推进和落实。

\section{2 .3 突出重点, 推进发展}

标准化规划设计要按照习总书记的 “各项规划都要体现节约集约利用资源、最大限度发挥资 金使用效益的原则, 不要贪大求全、乱铺摊子” 的要求, 因此规划设计要突出重点, 抓大放 小。此外, 通过本次标准化规划设计, 可形成一套可参照的冬奥会协办模式, 全国可复制, 从而实现资金使用效益的最大化。

\section{3 安全原则}

安全是人类最基本的需要之一, 安全性问题也是冬奥会筹办过程中最基本也是最关键的问题, 因此在标准化规划中也应该注重考虑。这里所说的安全既包括各种食品、药品、公共服务设 施的安全, 也包括紧急事件应急处理等方面的安全。应急处置措施方面值得借鉴《眉山市 “十 三五” 质量发展规划》种 “主要发展任务” 部分的第二节，“坚持惠民共享严管质量安全” 的 第二条 “强化风险防控” 中的 “健全质量安全风险监测、分析研判、预警、评估、信息通报和 应急处置机制, 有效防范和处置食品药品、危化品、建设工程、环境污染和特种设备等质量 安全突发事件, 切实增强事前防范、事中控制和事后处置能力。加强风险信息收集, 健全产 品伤害监测系统、质量安全信息舆情监控系统和风险预警公共技术服务平台, 全方位、多渠 道收集网络信息、微信信息、实验室检测数据统计分析等风险信息。加强应急救援体系建设, 制定完善质量安全风险应急预案, 做到风险早发现、早研判、早预警、早处置。探索质量安 全多元救济机制, 建立产品侵权损害赔偿、产品质量安全责任保险、企业质量风险救济基金 和社会救助救济机制，保障质量安全事故受害者及时得到合理补偿”相关内容。

\section{4 关于创新}

总体上, 通过关注相近城市标准化发展规划, 参考借鉴其适用于张家口市的先进理念和做法 基础上, 结合针对张家口市特点进行创新设计是一种有效途径。比如在宣传、营造良好舆论 氛围方面，可借鉴广西壮族自治区通过组织好 “世界标准日”、“科技活动周”、“科普日” 等重大主题宣传活动, 来提高全社会标准化意识, 创新提出适合张家口市的宣传推广手段。在 鼓励扶持政策方面, 吉林省提出了一些加强奖励和扶持的政策措施, 比如其在《吉林省标准

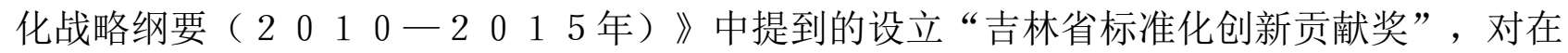
标准化工作中做出突出贡献的单位和个人给予表彰奖励等措施。在此基础上, 可以结合与张 家口类似的区域发展方式, 规划路径进行参考性分析。通过对典型地区, 及其产业特点的分 析，提炼、设计张家口市标准化发展和质量提升规划中的创新模式。

综上, 以制定张家口市标准化规划考虑的原则为例, 进行了具体分析。多数原则对其他城市 标准化规划制定具有一定的参考价值, 但也不都完全适用, 特定地区还需要进行具体的适用 性分析。 


\section{5. 关于规划的技术咨询}

各城市在进行标准化规划制定过程中为了提升规划的质量和水平往往大量进行技术咨询、论 证、评审等, 甚至直接委托、外包给技术咨询机构进行规划的撰写。然而, 总体上, 由于受 到时间限制, 加之调研的局限性, 技术咨询机构很难对相关城市了解的特别详细, 因此由技 术咨询机构起草的规划一般会从总体上、宏观上, 并且很可能更多地倾向于从规划、标准化 等角度进行统筹设计, 很难特别详细。更加具体的方案、措施, 还需要当地相关部门在相关 规划基础上进一步细化和完善。例如《海南省人民政府关于实施标准化战略的意见》（琼府 （2011〕15号）在 “（四）加强责任落实” 部分提出, “省政府对实施标准化战略实行目标管 理责任制。各级政府、各有关部门要把实施标准化战略纳入当地国民经济和社会发展规划, 并根据标准化战略意见的要求, 提出本地区、本部门实施标准化战略的具体方案”。因此, 进行了技术咨询的地方政府可以在技术咨询机构规划基础上进一步研究完善, 制定出适用性、 指导性更强的城市标准化规划的实施方案, 这样才更顺应十九大提出的高质量发展要求。

\section{6. 总结}

我国经济已经转向高质量发展阶段, 发展方式正在转变, 经济结构优化、产业结构调整已是 必然趋势。标准化在当今社会经济发展中发挥了越来越大的作用, 通过城市标准化发展规划 的制定和实施, 有效促进了我国城市发展的规范化和协调化, 提升了各类产品、服务的质量, 优化了产业结构, 收到了良好的经济和社会效益。然而, 城市标准化发展规划的制定是一项 系统工程, 需要考虑的原则和因素很多, 本文罗列有限, 还有待于进一步分析和挖掘。参考 性做法也不一定是最优方案, 特定地区还需要进行针对性分析。另外, 技术咨询是提高政府 管理有效性、决策科学性的可行手段, 然而, 技术咨询只有与自身研究密切配合、相互促进, 才能更大的提升城市标准化发展规划针对性和适用性。

\section{Acknowledgements}

This research was financially supported by the analysis of standard problems and countermeasures in Sino-us trade frictions (Grant NO. 572018Y-5936), the research of standardized strategy (Grant NO. 572018B-6053), and the President Foundation of CNIS (Grant NO. 572016Y-4675).

\section{References}

[1]. Xingjian Zhu. Exploring a new mode of economic work and creating a new situation of transformation and Upgrading -- Thinking about the construction of demonstration zone for industrial transformation and upgrading in the new era $[\mathrm{J}]$, China Economic Trade Herald, 2018:46.

[2]. GB /T 20000. 1- 2014 Guide to standardization work part 1: general terminology for standardization and related activities.

[3]. Lobo Mai. Standardizology: Science Theory of Standardization [M], Science press, 2017: 26.

[4]. China National Institute of Standardization. International Standardization Development Report, 2014: 120. 